\title{
NexusHaus: UT/TUM Solar Decathlon house
}

\author{
M. Garrison ${ }^{1}$, W. Lang ${ }^{2}$, P. Liedl ${ }^{1}$ \& A. Pyrek ${ }^{1}$ \\ ${ }^{1}$ School of Architecture, The University of Texas at Austin, USA \\ ${ }^{2}$ Department of Architecture, Technical University of Munich, Germany
}

\begin{abstract}
The University of Texas at Austin and the Technical University of Munich 2015 Solar Decathlon house, is called NexusHaus because it combines UT Austin and TUM students in a modular green building that demonstrates transformative technologies in Zero Net Energy, Positive Net Water and Carbon Neutrality. The NexusHaus building configuration consists of two modular rectangular structures with layers and components attached that interact with the environment to provide a resource-efficient and affordable home. The thin width of each module allows for ease of highway transportation and the shape configuration achieves energy and spatial efficiency through indoor/outdoor living, shading, cross ventilation and daylighting. The roof mounted $6 \mathrm{~kW}$ photovoltaic system provides for the home's power needs. And the roof canopy collects rainwater to provide for the home's water needs. The extensive use of wood in the design enables the embodied energy of the home building materials to be more carbon neutral. Keywords: zero net energy, positive net water, carbon neutral.
\end{abstract}

\section{Introduction}

The NexusHaus design form affects the energy performance of the house. The building orientation of the modules is designed to take best advantage of the southern exposure during the winter, and to reduce the over-bearing intensity of the sun in the afternoon hours during the hot summer months (Figures 1 and 2). Layered onto, and around the modules are a series of rain screens, canopies and arrays that either passively filter the sun's rays before they strike the building's skin, or actively harvest solar energy to power the systems and appliances within the home, or to harvest rainwater and support an edible permaculture landscape. These layers also extend the threshold of the house into the landscape, providing a screen for the flow of indoor/outdoor living. Three large nine-foot wide folding 
glass "Nanawalls" systems open up to connect the modules to the outdoor deck enhancing a spacious sensibility to the modest 784 square foot conditioned house (U.S. Solar Decathlon [1]).

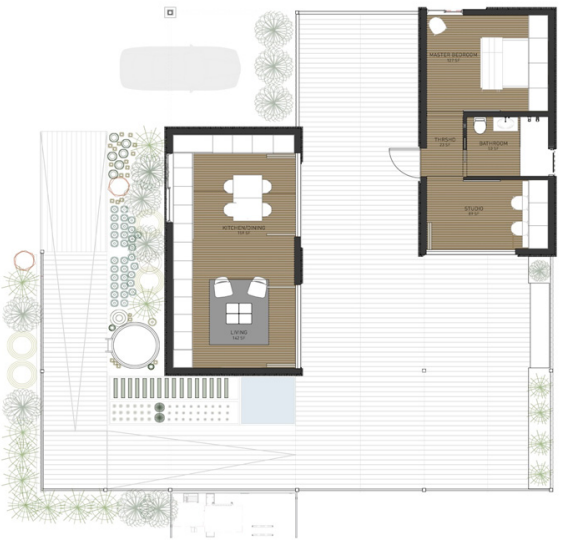

Figure 1: NexusHaus floor plan.

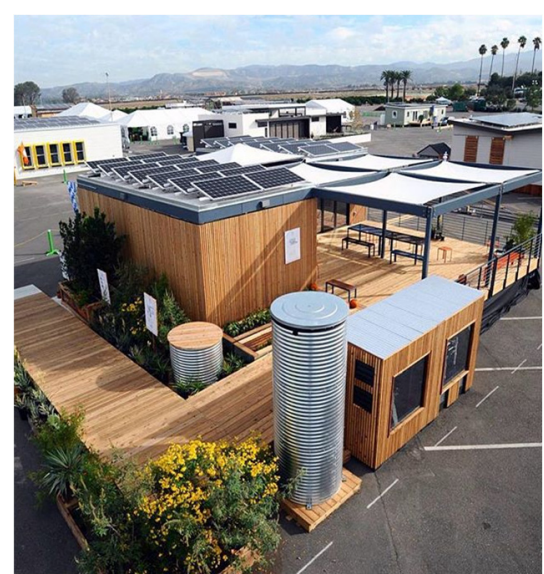

Figure 2: NexusHaus exterior view.

The modular structure consists of two fourteen-feet wide by twenty-eight-footlong structures in a binuclear configuration connected together by a covered shade canopy and outdoor deck. One of the modules is designated as the day module and contains of the living room, dining room and the kitchen. The other module is designated as the night module and contains of two bedrooms with a bathroom in-between. A twelve-foot by twelve-foot breezeway with a covered canopy and pull down privacy screens connects the two modules for ease of movement between the day and night zones of the house. A large 676 square foot covered deck is located on the southeast side of the house to enhance outdoor living using a "dog-trot ventilation porch" configuration.

\section{Zero net energy}

Energy efficient design procedures for the NexusHaus [2], started with energy conservation first. R-30 wall and R-40 roof insulation, weather stripping, LED lighting, Energy Star rated appliances, a high SEER hydronic mechanical system, energy recovery ventilators and an overall building "design with climate" strategy combine to reduce the building thermal load to less than 1 ton of conditioning per 800 square foot of conditioned living space. Because the house is extremely energy efficient the house is able to generate enough power from a $6 \mathrm{~kW}$ roofmounted PV system that it not only generates enough power for the house and to charge an EV BMWi3 electric vehicle to travel 25 miles per day, it has extra power production that is sent back into the community electric grid. 


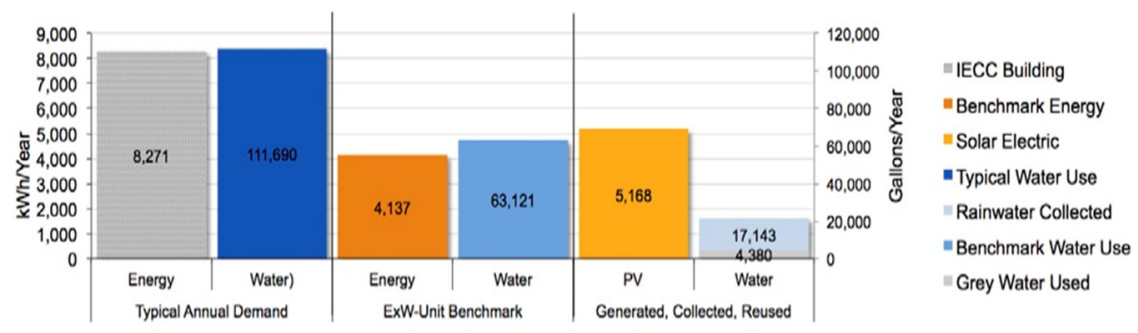

Figure 3: Energy use comparison.

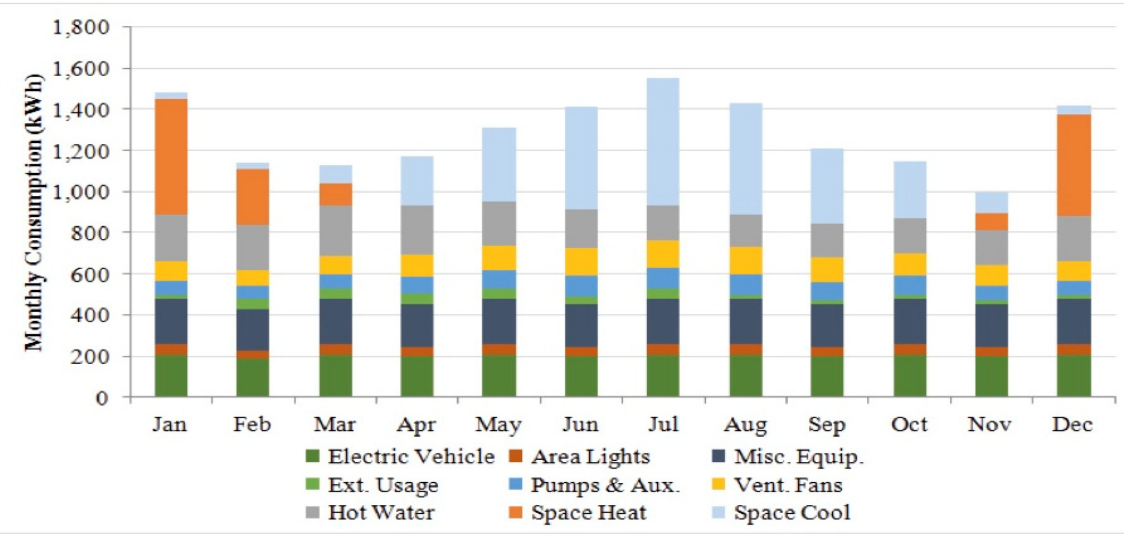

Figure 4: NexusHaus energy use.

To alleviate afternoon electricity grid congestion, and avoid higher-priced power, the house incorporates a stratified water thermal storage system to shift air conditioning load off-peak to the early morning hours. The system is an integrated thermal energy and rainwater storage (ITHERST) system that is combined with the residential air source chiller/heat pump with hydronic distribution.

\section{Positive net water}

Water conservation is mandatory in both Central Texas and Southern California and as such the NexusHaus design harvests more rainwater than it needs to meet its potable water needs (Malinowski et al. [3] and Webber [4]). The roof of the house and the breezeway canopy are designed to collect over 17,000-gallons of water per year in Austin, Texas (Texas Water Development Board [5, 6]). This water is stored in a 10,000-gallon polyethylene bladder tank located under the outdoor deck. The rainwater is treated using a 5-micron paper filter and a charcoal filter as well as disinfected using an ultraviolet light. The positive water systems include a potable rainwater collection system, greywater collection and irrigation system, and an AC condensate collection. These three segments of the 
water system are controlled through a series of volume balances that track the water collected, held, and consumed by the household on a daily basis. Figure 5 shows the rainwater harvesting and wastewater reuse portion of the ITHERST system for NexusHaus (Dincer and Rosen [7]). The house captures rainwater to supply all of its potable water needs, relying on a small city water refill line only for backup during long dry spells. The potable rainwater harvesting system minimizes added stress to the region's water supplies, and minimizes the additional load on the existing neighborhood water and wastewater infrastructure. A secondary thermal storage tank acts as additional storage volume for rainwater, giving the system extra capacity while also providing beneficial thermal storage and load shifting.

\section{The Energy x Water Nexus House: Water Systems Schematic}

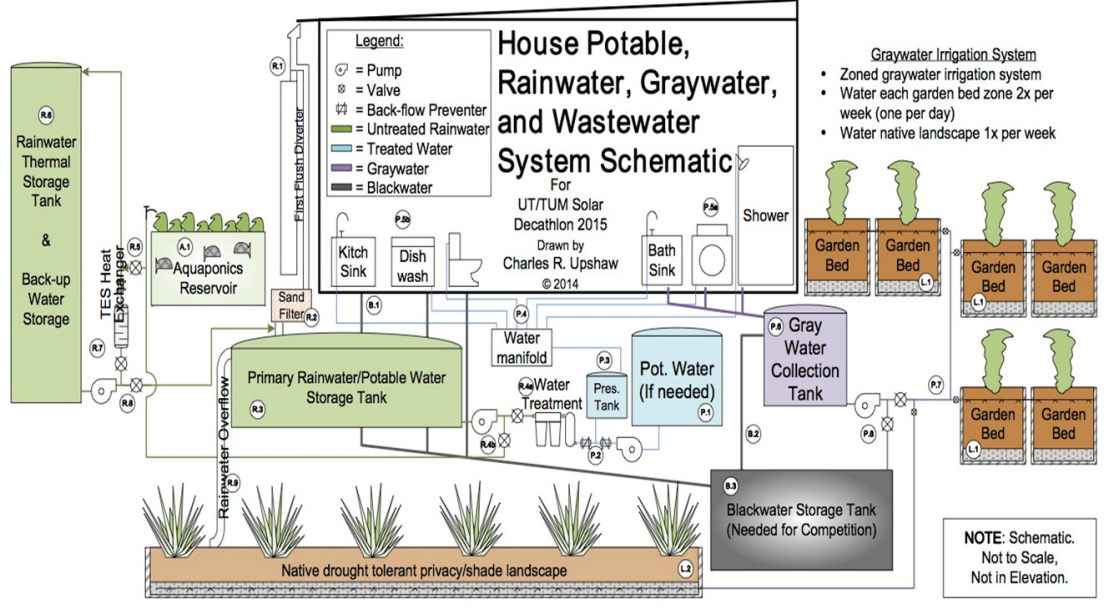

Figure 5: ITHerst NexusHaus water systems.

Another large use of water is in the water irrigation requirements of the food we consume. NexusHaus employs an aquaponic garden in which fish and vegetables are grown together in a constructed aquatic ecosystem. The effluent from the fish fertilizes the water which is pumped to vegetable grow beds where bacteria convert the effluent into usable nutrients for the plants. The plants in turn absorb nutrients from the water, thereby purifying the water, which flows back to the fish.

\section{Towards carbon neutral}

Looking at the NexusHaus from a Life Cycle Analysis (LCA) [8], allowed us to evaluate different building material options throughout the NexusHaus' lifetime, 
from construction through operation until disassembly. In each phase, an input and output inventory of environmental impacts for different building materials were calculated using Tally, a software application [9]. Tally is an LCA tool that calculates the environmental impacts of different building materials and their assemblies. Tally was developed in 2008 by KT Innovations partnered with Autodesk Sustainability Solutions and PE International in response to a growing industry awareness of life cycle considerations. Tally is an application that works with Autodesk Revit and helps quantify the environmental impacts of the building materials for the whole building analysis. Finally, Tally methodology is consistent with the latest LCA standards ISO 14040-14044.

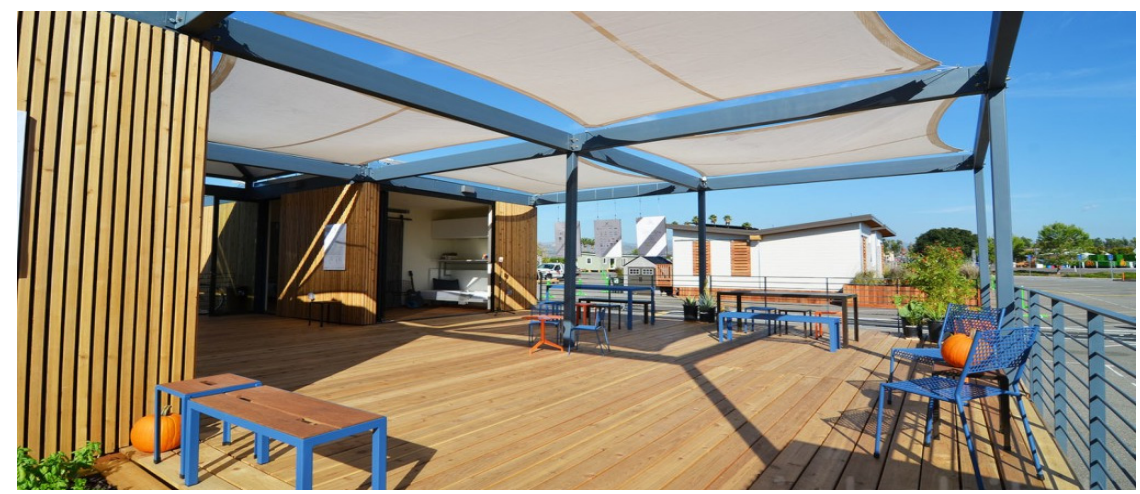

Figure 6: NexusHaus features extensive use of wood.

To start our analysis, we first built three simplified Revit model versions of the NexusHaus design to designate the materials and construction systems we wanted to compare and analyze with Tally. Our first step in the decision tree was to choose the main material for the construction of the building: wood, brick or concrete. The results are based on an assumption of 40 years' building service life, which is reached by all compared materials under normal circumstances without replacements. Consequently, we did not consider any maintenance or replacement efforts. The calculated savings result from a total wall area of $840 \mathrm{ft} 2$. Figure 7 shows the results obtained for different materials and resultant performance indicators and impact categories.

The results of the TALLY analysis documented that wood was our clear choice for NexusHaus. Wood weighs much less than brick or concrete. This grants major benefits for the transport in case of prefabrication. It also outperforms both brick and concrete in the impact category of Global Warming Potential and the impact category of Non-renewable Primary Energy Demand. By scaling up the results for NexusHaus, we determined that the amount of $\mathrm{CO}_{2}$ saved by using wood as compared to brick is the same amount as generated by driving a mid-sized automobile 11,900 miles, which would bring you from Austin to the other side of the planet, the Himalayas. Also, the Non Renewable Primary Energy saved equals 889 gallons of gasoline. 


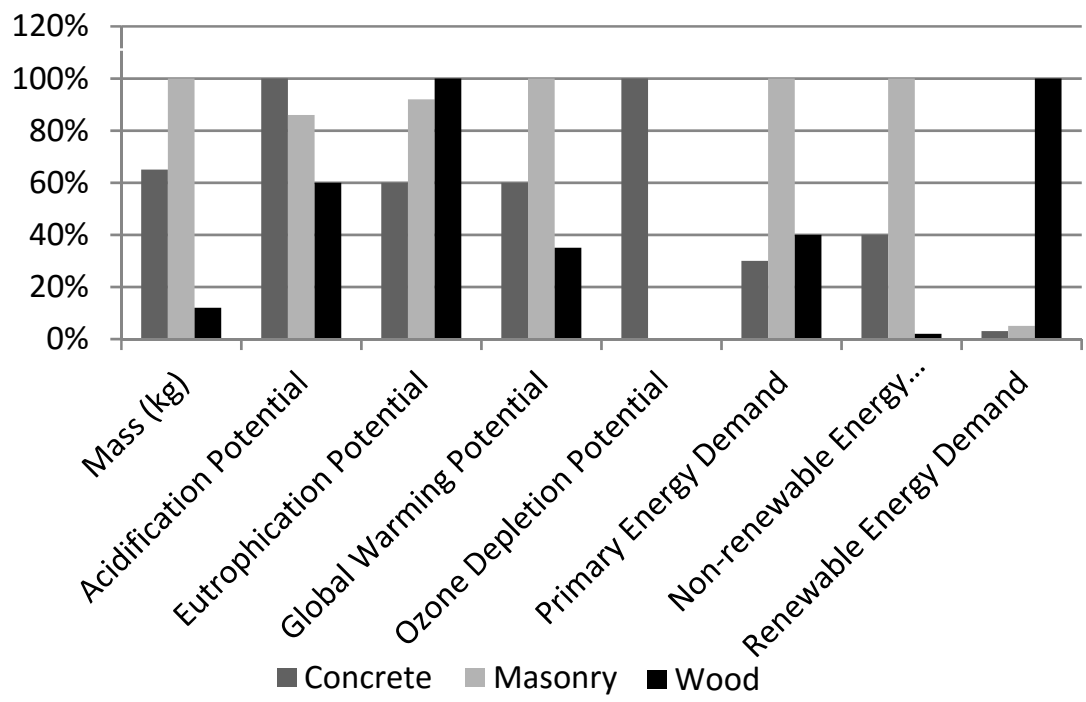

Figure 7: LCA results for materials.

Our design of the NexusHaus features an extensive use of wood both as the structure for the house and as a finish material because we determined that wood has many positive characteristics, including low embodied energy, low carbon impact, and sustainability. Carbon is sequestered in tress and remains sequestered in the lumber through the life of the building. Forest resources are renewable and with proper management a flow of wood products can be maintained indefinitely. Using wood from sustainably managed forests actually reduces carbon dioxide emissions, as the carbon dioxide stored by the forest and in the timber product outweighs any carbon dioxide created during the production of the product. Each ton of timber used instead of other building materials (like steel) saves a ton of carbon dioxide.

Using the amount of $\mathrm{CO}_{2}$ sequestered in the wood used in the construction of NexusHaus, the materials specified balanced the $\mathrm{CO}_{2}$ generated in the manufacturing of our other building materials used in the house such that NexusHaus is moving towards carbon neutrality (Tosi et al. [10]).

\section{Results and performance evaluation}

Two simplified models were developed by team member Charles Upshaw to perform an initial assessment of the system performance for both the thermal storage and potable rainwater collection systems in the NexusHaus (Upshaw et al. [11]). The analysis was twofold: 1) provide a first approximation of the TES system performance of the described ITHERST system, 2) estimate the water savings for the rainwater collection system, and assess the impact of utilizing a portion of it for thermal storage. A step-wise hourly thermodynamic model of the thermal storage system is deliberated to assess on-peak performance, and a daily 
volume-balance model of supplementary water collection and consumption is provided to assess water savings potential. The results are convincing: Comparing the modeled cooling load to that of a typical Austin house shows that the solar decathlon house used in this analysis represents a smaller and more thermally efficient design scenario. Analysis performed suggests that the proposed ITHERST system could reduce the on-peak cooling load (compared to the same system without TES) by over 75\%, when operating in Austin, Texas. Based on this limited analysis, there appears to be minimum tank volume needed to provide maximum peak load reduction (approximately $1500 \mathrm{~L}$ or 400 gallons). However, there does not appear to be any further benefits gained from having a tank significantly larger than the minimum.

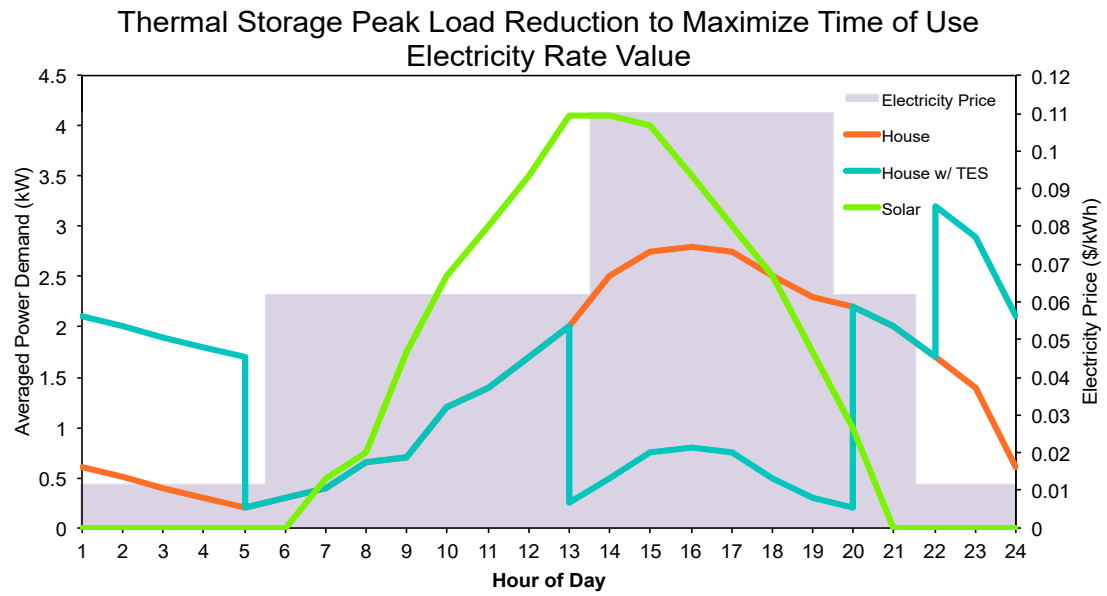

Figure 8: Thermal storage reduces the overall load from the NexusHaus to minimize consumption during high electricity price hours, and maximize the utility of the house's solar electricity production.

The rainwater collection and consumption analysis indicated that the system can reduce municipal water consumption significantly, but that it would not be able to reach full water independence if it were routinely facing low rainfall rates as those during 2011 in Texas. The "maximum reduction in municipal water consumption was $89 \%$, and was achieved by total storage volumes of 8,000 gallons (30,283 L) and larger" (Upshaw et al. [11]).

The thermal storage operation had a minor impact on overall rainwater collection performance, increasing municipal consumption from $47 \%$ (no TES) to $51 \%$ (with TES) at the lowest system volumes level; at volumes of 5,000 gallons $(18,927 \mathrm{~L})$ and higher, thermal storage operation had zero impact on the municipal water savings" (Figure 9). 


\section{Rainwater Captured and Spilled, and Municipal Water \\ Bought, vs. Tank Size \\ for 2011-2013}

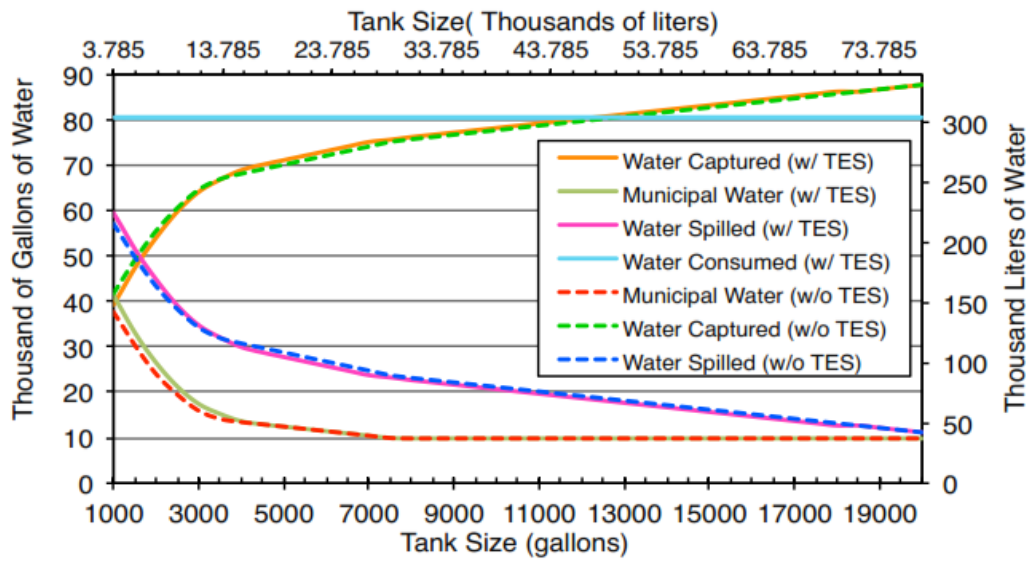

Figure 9: Rainwater captured increases and both rainwater spilled and municipal make-up water consumed decrease non-linearly with increasing storage tank size. This figure shows the impact of using a portion of the volume for thermal storage has little impact to no impact on the ability of the rainwater catchment system to reduce municipal water consumption.

\section{Conclusion}

The NexusHaus demonstrates an affordable completely solar-powered and water efficient home, and the innovations of the house serve as catalysts for change, leading the residential housing industry toward more sustainable practices while addressing the need for well-designed, appropriately diverse, economically viable, and environmentally responsible housing. The solar decathlon jury has commended the NexusHaus team for its highly innovative water treatment system, integrated rainwater collection and thermal storage system, high efficiency chiller and student designed smart home control system. The developed models to perform an initial assessment of the system suggest that these integrated systems have the technical potential to significantly reduce electric peak load demand and water consumption from residential houses. While the magnitude of the results from the case study analysis in this paper are not directly applicable to different sized houses or locations, the relative load reduction and water savings (approximately $75 \%$ peak load reduction, approximately $90 \%$ municipal water savings) could be reasonably achieved on larger, more traditional, homes given proper system sizing and water efficiency measures.

NexusHaus has been shipped to McDonald Observatory in West Texas to house scientists and other university staff members, where further monitoring and 
experimental evaluation will be carried on in order to further investigate the building performance.

\section{References}

[1] The U.S. Dept. of Energy Solar Decathlon 2015 Competition, www.solardecathlon.gov, The S. Department of Energy, last accessed: January, 2016.

[2] NexusHaus, www.Nexushaus.com, The University of Texas at Austin, January 2016.

[3] Malinowski, P. A., Stillwell, A. S., Wu, J. S. \& Schwarz, P. M. EnergyWater Nexus: Potential Energy Savings and Implications for Sustainable Integrated Water Management in Urban Areas from Rainwater Harvesting and Gray-Water Reuse. Journal of Water Resources Planning and Management, A4015003, 2015.

[4] Webber, M. (M.E.). Thirst for Power: Energy, Water and Human Survival. Yale University Press, 2016.

[5] Texas Water Development Board. The Texas Manual on Rainwater Harvesting. Technical Report, Texas Water Development Board, 2005.

[6] Texas Water Development Board. Rainwater Harvesting Potential and Guidelines for Texas Report to the 80th Legislature. Technical Report November, State of Texas Rainwater Harvesting Evaluation Committee, 2006.

[7] Dincer I.\& Rosen, M.A. Thermal Energy Storage: Systems and Applications, John Wiley Ltd., 2010.

[8] Environmental management - Life cycle assessment - Principles and framework (ISO 14040:2006).

[9] TALLY. Computer software. Http://choosetally.com/. Vers. 2014.12.10.01. KT Innovations, PE International, and Autodesk, n.d. Web.

[10] Tosi, A., Hanisch, C., Maia, I., Park, J., Maric, M., Recher, M. \& Urena, M. "Building Systems: Life Cycle Analysis of the NexusHaus, Materials, Photovoltaics, Construction \& Transport, Integrated Life Cycle Analysis of NexusHaus, Technische Universitat Munchen, Institute for Energy Efficient and Sustainable Planning and Building, Munich Germany, March 2015.

[11] Upshaw, C.R., Rhodes, J.D. \& Webber, M.E.(2016).Modeling Electric Load and Water Consumption Impacts from an Integrated Thermal Energy and Rainwater Storage System for Residential Buildings in Texas, 10.1016/j.apenergy, 2016. 